\title{
The Effect of Bariatric Surgery on Patients with Chronic Disease in KSMC
}

\author{
Abdullah Ahmed Aloraini ", Abdulelah Sulaiman Alsughayyir, Abdullah Khaled Alamri, Haitham Shayea \\ Alshayea, Mohammed AlMesned
}

Family Medicine Academy, King Saud Medical City (KSMC), Riyadh 12746, Saudi Arabia

*Corresponding author: Abdullah Ahmed Aloraini; aa.aloraini@ksmc.med.sa

Received: 06 August 2021;

Accepted: 15 August 2021;

Published: 18 August 2021

\begin{abstract}
Background: Obesity is a fast-growing global epidemic; it is associated with several comorbidities, including diabetes mellitus, hypertension, and dyslipidemia. Bariatric surgery is increasingly used due to its positive impacts on most of the comorbidities such as type 2 diabetes mellitus in patients with morbid obesity as it improves glycemia, lipids,blood pressure, andinflammation. Aim: To assess the effect of bariatric surgery on diabetic and dyslipidemic patients. Method: This is a retrospective study conducted on diabetic and dyslipidemic patients who underwent bariatric surgery. The study included the data of patients from 2009 to 2018 from KSMC. SPSS was used to analyze the collected data. $\underline{\text { Results: }}$ There were 808 diabetic patients included with a mean \pm SD age of $42.1 \pm 11.05$ years old, and 25 dyslipidemic patients with a mean \pm SD age of $45.4 \pm 8.2$ years. There were $72.4 \%$ of diabetic patients and $52 \%$ of dyslipidemic patients completed the treatment. Regarding diabetic patients, the outcome of patients was significantly associated with nationality $(\mathrm{P}<0.0001)$ and the mean age of patients $(\mathrm{P}<0.0001)$. The mean age had a significant impact on the outcome of the diabetic patients $(\mathrm{P}=<0.0001)$ and had no effect in the case of the dyslipidemic patients $(\mathrm{P}=0.37)$. Conclusion: Bariatric surgery has a significant impact on chronic diseases such as diabetes and dyslipidemia, with a higher impact on diabetes compared to dyslipidemia.
\end{abstract}

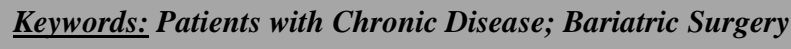

\section{Introduction}

Obesity is a rising pandemic responsible for important health and socioeconomic outcomes. Its prevalence has nearly tripled since 1975 due to decreased physical activity and increased consumption of energy-dense foods. In worldwide estimation in 2016, more than 1.9 billion adult individuals, 18 years and older, were overweight. Of these, over 650 million were obese ${ }^{[1]}$.

The international changes in the food system have also affected the developing countries in a nutritional transition marked by junk food and an increasingly sedentary lifestyle ${ }^{[2]}$. Because of the accelerated dietary change, obesity and overweight are found in both poor and wealthy populations ${ }^{[3,4]}$. Socioeconomic factors affect the occurrence of obesity in a given community ${ }^{[5]}$. Recent articles have shown that, in western-type lifestyle countries, economically weaker regions and socially disadvantaged communities are usually affected by obesity more than relatively affluent people.

In Saudi Arabia, this trend has been recently reported due to the lifestyle transition from a traditional Saudi lifestyle towards a more western lifestyle. Also, recent articles of the health studies show obesity is more frequent in children and adults of low socioeconomic situations ${ }^{[6]}$. In the $21^{\text {st }}$ century, overweight has become one of the most common health issues, as it will cause a high prevalence of cardiovascular disease in developing countries [7]. Obesity is a serious health concern and causes an increased risk of morbidity and mortality from conditions such as diabetes and hypertension. Substantial evidence has been reported concerning the increase of heart failure and mortality incidence concerning adiposity and obesity ${ }^{[8,9]}$. Weight management has been related to significant health benefits, increased physical fitness, and psychosocial effects such as the reduced risk for the development of eating disorders ${ }^{[10]}$. It is worth mentioning that diabetes mellitus prevalence is growing alongside obesity, with an estimation from 422-650 millions people worldwide in $2014^{[11]}$.

Bariatric surgery combined with optimal medical therapy is more effective than a combination of lifestyle and medication interventions for weight loss ${ }^{[12]}$. Bariatric surgery results in sustained weight loss for up to 20 years, with a reduction in mortality compared with medical care with diets, exercise, and medication ${ }^{[13]}$.

Also, obesity can be treated non-surgically or by means of bariatric surgery ${ }^{[14]}$, which has been widely demonstrated to cause continued weight loss and a reduction in comorbidities ${ }^{[15]}$, including type II diabetes, hypertension, and hyperlipidemia ${ }^{[16]}$. There is increasing evidence that bariatric surgery is a substantial 
means of achieving long-term weight control ${ }^{[17]}$, and the current guidelines suggest it for individuals with a body mass index of $>40$ (>35 when linked to one or more comorbid diseases) ${ }^{[18,19]}$.

The number of centers offering bariatric surgery has increased globally over the last three years ${ }^{[18]}$, and the most commonly used techniques are Roux-en-Y gastric bypass surgery, sleeve gastrectomy, and laparoscopic adjustable gastric banding ${ }^{[20]}$. Although still not void of risks, the risks have been decreased due to increasing experience and advances in perioperative care ${ }^{[18,19]}$. Aleassa et al. (2019) performed a study to evaluate the effect of revisional surgery on the glycemic status of patients with T2DM who either failed to remit or relapsed after an initial remission following bariatric surgery. The results concluded that conversion of vertical banded gastroplasty, adjustable gastric banding, and sleeve gastrectomy to Roux-en-Y gastric bypass was related to diabetes remission rates of $35 \%, 35.7 \%$, and $23.1 \%$, respectively [21].

Shimada et al. (2017) performed a self-controlled case series study of obese individuals with hypertension who subjected to bariatric surgery. The study included 980 obese patients with hypertension who underwent bariatric surgery. The median age was 48 years, $74 \%$ were female. During the reference period, $17.8 \%$ had a primary outcome (the study reported at least one acute care use for hypertension related disease in $17.8 \%$ of the study population).

The risk continued unchanged in the following 12-month pre-surgery period $(18.2 \%)$ adjusted odds ratio [aOR] 1.02 . However, in the initial 12-month following bariatric surgery, the risk significantly reduced by $10.5 \%$. Similarly, the risk continued to significantly decrease in the 13-24 months after bariatric surgery by $12.9 \%$. On the other hand, there was no notable decline in the risk among obese subjects who subjected to non-bariatric surgery (i.e., hysterectomy, cholecystectomy, spinal fusion, or mastectomy) ${ }^{[22]}$.

Ricci et al. (2015) performed a random impact of metaanalysis, and dose-response meta-regression was applied to estimate weight loss and the prospect of type II diabetes mellitus, hypertension, and hyperlipidemia, 2-5 years following bariatric surgery. The study concluded that the body mass index at the end of the follow-up period was 31.7.

Also, the prospect of type II diabetes, hyperlipidemia, and hypertension reduced after bariatric surgery, with relative risks of, respectively, 0.33, 0.33, and $0.54^{[23]}$. Kashyap et al. (2013) performed a study to estimate the results of two bariatric procedures in comparison to intensive medical therapy on $\beta$-cell function and body composition. The study concluded that glycemic control improved in all groups at 24 months, with a mean $\mathrm{HbA1c}$ of $7.1 \pm 0.8 \%$ for sleeve gastrectomy, $6.7 \pm 1.2 \%$ for gastric bypass, and $8.4 \pm 2.3 \%$ for intensive medical therapy. A decrease in body fat was similar for both surgery groups, with a greater absolute decrease in truncal fat in gastric bypass in comparison with sleeve gastrectomy $(-16$ vs. $-10 \% ; \mathrm{P}=0.04)$. The sensitivity of insulin raised from baseline in gastric bypass (2.7-fold; $\mathrm{P}=$ 0.004) and did not change in sleeve gastrectomy or intensive medical therapy. $\beta$-Cell function increased 5.8 -fold in gastric bypass from baseline, was markedly higher than intensive medical therapy $(\mathrm{P}=0.001)$, and was not different between sleeve gastrectomy versus intensive medical therapy $(\mathrm{P}=0.30)$. At 24 months, $\beta$-cell function inversely correlated with truncal fat and prandial free fatty acid levels ${ }^{[24]}$.

\section{Methods}

- Study design: Retrospective cohort study.

- Study population: Male and female adult obese patients with diabetes mellitus and dyslipidemia attending KSMC.

- Participant's age: From 18 and above.

- Inclusion criteria: Diabetes mellitus and dyslipidemia.

- Exclusion criteria: Mentally ill patients and patient with lost follow ups.

- Study groups: One group of obese patients with diabetes mellitus and dyslipidemia.

- Sample size: 500

- Study tool: will perform a retrospective study using administrative data from 2009-2018. The study was included de male and female adult obese patients with diabetes mellitus and dyslipidemia attending KSMC which create variables for description to be used in modeling outcomes, including demographics (age, sex), utilization variables (hospitalizations, outpatient visits, medical and pharmacy payments), and other indicators of health status, including which sort of bariatric surgery has been done. Will compare each patient's risk of morbidity and mortality from conditions such as diabetes and dyslipidemia before and after bariatric surgery.

- Ethical consideration: All data was dealt with utmost confidential manner. Ethical approval was sought from the Institutional Review Board (IRB) center in KSMC. The researcher was the only persons who would review the data and all names and identifying demographics were anonymized for confidentiality.

- Statistical Analysis: The main variables which includes Age, gender and BMI were collected and saved in an Excel sheet,

- $\quad \mathrm{T}$ test or chi square to differentiate between the means before and after was applied accordingly, moreover descriptive analysis for some variables to provide the frequency and percentage were demonstrated by using SPSS.

\section{Results}

A total of 808 diabetic patients; the mean \pm SD of their age was $42.1 \pm 11.05$ years old. There were 569(70.4\%) females, and the remaining percentage was males. The majority of patients were Saudi $720(89.1 \%$ ), whereas the other nationalities represented fewer percent. Most of the patients completed the treatment $585(72.4 \%)$, whereas $205(25.4 \%)$ required follow-up OPD therapy, and $18(2.2 \%)$ died, table1.

Table 1: Demographic characters of included patients

\begin{tabular}{|l|l|l|l|}
\hline \multicolumn{2}{|l|}{} & N (808) & \% \\
\hline \multicolumn{2}{|l|}{ Age (Mean \pm SD) } & 42.10 & 11.05 \\
\hline \multirow{2}{*}{ Gender } & Female & 569 & $70.4 \%$ \\
\cline { 2 - 5 } & Male & 239 & $29.6 \%$ \\
\hline
\end{tabular}




\begin{tabular}{|c|c|c|c|}
\hline \multirow[t]{18}{*}{ Nationality } & American & 1 & $0.1 \%$ \\
\hline & Egyptian & 26 & $3.2 \%$ \\
\hline & Eritrean & 2 & $0.2 \%$ \\
\hline & Filipino & 2 & $0.2 \%$ \\
\hline & Indian & 1 & $0.1 \%$ \\
\hline & Indonesian & 2 & $0.2 \%$ \\
\hline & Jordanian & 2 & $0.2 \%$ \\
\hline & Mali & 1 & $0.1 \%$ \\
\hline & Morocco & 1 & $0.1 \%$ \\
\hline & Muqeem & 2 & $0.2 \%$ \\
\hline & Nigerian & 1 & $0.1 \%$ \\
\hline & Omani & 1 & $0.1 \%$ \\
\hline & Palestinian & 14 & $1.7 \%$ \\
\hline & Saudi & 720 & $89.1 \%$ \\
\hline & Somalian & 1 & $0.1 \%$ \\
\hline & Sudanese & 12 & $1.5 \%$ \\
\hline & Syrian & 9 & $1.1 \%$ \\
\hline & Yemeni & 10 & $1.2 \%$ \\
\hline \multirow[t]{3}{*}{ Status } & Death & 18 & $2.2 \%$ \\
\hline & Follow-up OPD therapy required. & 205 & $25.4 \%$ \\
\hline & Treatment completed. & 585 & $72.4 \%$ \\
\hline
\end{tabular}

The correlations between the outcome of treatment and the demographics of the patients are shown in table2. There was no significant difference in the outcome regarding the gender
$(\mathrm{P}=0.15)$, whereas there were significant differences in the outcomes of patients regarding nationality $(\mathrm{P}<0.0001)$, and the mean age of the patients $(\mathrm{P}<0.0001)$

Table C 2: Correlations between patient's demographics and surgical outcome

\begin{tabular}{|c|c|c|c|c|c|c|c|c|}
\hline & & \multicolumn{6}{|c|}{ Status } & \multirow{3}{*}{ P-value } \\
\hline & & \multicolumn{2}{|c|}{ Death } & \multicolumn{2}{|c|}{$\begin{array}{l}\text { Follow-up OPD } \\
\text { therapy required. }\end{array}$} & \multicolumn{2}{|c|}{ Treatment completed. } & \\
\hline & & $\mathrm{N}$ & $\%$ & $\mathrm{~N}$ & $\%$ & $\mathrm{~N}$ & $\%$ & \\
\hline \multirow[t]{2}{*}{ Gender } & Female & 9 & $50.0 \%$ & 145 & $70.7 \%$ & 415 & $70.9 \%$ & \multirow[t]{2}{*}{0.15} \\
\hline & Male & 9 & $50.0 \%$ & 60 & $29.3 \%$ & 170 & $29.1 \%$ & \\
\hline \multirow[t]{18}{*}{ Nationality } & American & 0 & $0.0 \%$ & 0 & $0.0 \%$ & 1 & $0.2 \%$ & \multirow[t]{18}{*}{$<0.0001$} \\
\hline & Egyptian & 2 & $11.1 \%$ & 7 & $3.4 \%$ & 17 & $2.9 \%$ & \\
\hline & Eritrean & 1 & $5.6 \%$ & 1 & $0.5 \%$ & 0 & $0.0 \%$ & \\
\hline & Filipino & 1 & $5.6 \%$ & 0 & $0.0 \%$ & 1 & $0.2 \%$ & \\
\hline & Indian & 0 & $0.0 \%$ & 1 & $0.5 \%$ & 0 & $0.0 \%$ & \\
\hline & Indonesian & 0 & $0.0 \%$ & 1 & $0.5 \%$ & 1 & $0.2 \%$ & \\
\hline & Jordanian & 0 & $0.0 \%$ & 1 & $0.5 \%$ & 1 & $0.2 \%$ & \\
\hline & Mali & 0 & $0.0 \%$ & 0 & $0.0 \%$ & 1 & $0.2 \%$ & \\
\hline & Morocco & 1 & $5.6 \%$ & 0 & $0.0 \%$ & 0 & $0.0 \%$ & \\
\hline & Muqeem & 0 & $0.0 \%$ & 0 & $0.0 \%$ & 2 & $0.3 \%$ & \\
\hline & Nigerian & 0 & $0.0 \%$ & 1 & $0.5 \%$ & 0 & $0.0 \%$ & \\
\hline & Omani & 0 & $0.0 \%$ & 0 & $0.0 \%$ & 1 & $0.2 \%$ & \\
\hline & Palestinian & 0 & $0.0 \%$ & 2 & $1.0 \%$ & 12 & $2.1 \%$ & \\
\hline & Saudi & 10 & $55.6 \%$ & 183 & $89.3 \%$ & 527 & $90.1 \%$ & \\
\hline & Somalian & 0 & $0.0 \%$ & 0 & $0.0 \%$ & 1 & $0.2 \%$ & \\
\hline & Sudanese & 1 & $5.6 \%$ & 5 & $2.4 \%$ & 6 & $1.0 \%$ & \\
\hline & Syrian & 0 & $0.0 \%$ & 1 & $0.5 \%$ & 8 & $1.4 \%$ & \\
\hline & Yemeni & 2 & $11.1 \%$ & 2 & $1.0 \%$ & 6 & $1.0 \%$ & \\
\hline \multicolumn{2}{|c|}{ Age (Mean \pm SD) } & \multicolumn{2}{|c|}{$59.37 \pm 22.11$} & \multicolumn{2}{|c|}{$42 \pm 10.45$} & \multicolumn{2}{|c|}{$41.6 \pm 10.34$} & $<0.0001$ \\
\hline
\end{tabular}

There were 25 patients with dyslipidemia included in the study; their demographics are shown in table1. The mean \pm SD of the age of the patients was $45.4 \pm 8.2$ years old. Regarding nationality, the majority were Saudi patients, 22(88\%). More than one-half of the patients completed the treatment $13(52 \%)$, whereas $12(48 \%)$ required follow-up OPD therapy. Regarding age, the mean \pm SD age of the patients who completed the treatment was $46.1 \pm 10.7$ years, whereas that of the patients who required follow-up OPD therapy was $44.7 \pm 4.5$ years old $(\mathrm{P}=0.37)$ (figure1). 
Table 3: Demographics characters of dyslipidemic patients

\begin{tabular}{|l|l|l|l|}
\hline \multicolumn{2}{|l|}{} & Count (n=25) & Column N \% \\
\hline Age (Mean \pm SD) & Female & 45.4 & 8.2 \\
\hline \multirow{3}{*}{ Gender } & Male & 18 & $72.0 \%$ \\
\hline \multirow{5}{*}{ Nationality } & Bangladesh & 7 & $28.0 \%$ \\
\cline { 2 - 4 } & Egyptian & 1 & $4.0 \%$ \\
\cline { 2 - 4 } & Saudi & 1 & $4.0 \%$ \\
\cline { 2 - 4 } & Sudanese & 22 & $88.0 \%$ \\
\hline \multirow{3}{*}{ Status } & Follow-up OPD therapy required. & 1 & $4.0 \%$ \\
\cline { 2 - 4 } & Treatment completed & 12 & $48.0 \%$ \\
\hline
\end{tabular}

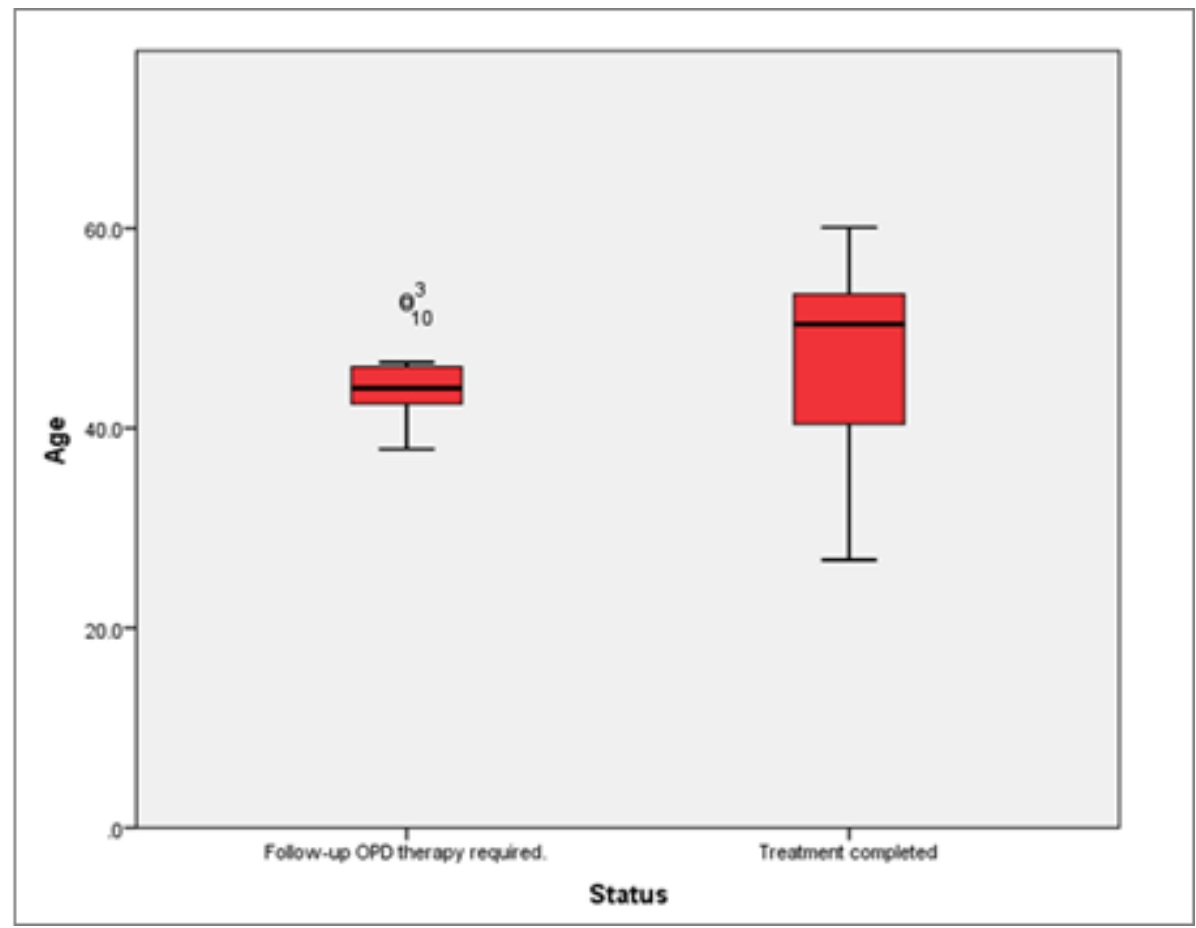

\section{Discussion}

Overweight and obesity are excessive and abnormal accumulation of fat that impairs the individuals 'health ${ }^{[25]}$. Obesity is associated with several complications and comorbidities, such as type2 diabetes mellitus (T2DM) ${ }^{[26]}$. Comorbidities were reported to be improved after the bariatric surgery; in a meta-analysis of 22094 patients who performed bariatric surgery, it was found that there was a significant weight loss of $61.2 \%$ and considerable improvements in several specific comorbidities such as diabetes, hyperlipidemia, hypertension, and obstructive sleep apnea ${ }^{[27]}$.

In the current study, regarding diabetic patients, most diabetic patients completed the treatment and required no followup OPD therapy $(72.4 \%)$, whereas a few percentages $(25.4 \%)$ required follow-up OPD treatment, and the least percent died. The outcome of bariatric surgery wasn't affected by the gender of the patients; however, the outcome was significantly affected by the nationality and the age of the patients. Saudi diabetic patients and those with a mean age of 41.6 years were significantly more prone to complete treatment with no requirement of follow-up OPD therapy. Bariatric surgery was found to be effective also on the patients with dyslipidemia, but with less efficacy compared to the diabetic patients, where more patients with dyslipidemia required follow-up OPD therapy (48\%). However, the age of the patient had no significant impact on the surgery outcomes.
Two long randomized controlled trials reported that bariatric surgery patients had significantly higher rates of remission of T2DM in two years ${ }^{[12,28]}$. A systematic review that included 621 studies and involved 135326 patients showed that most diabetic patients $(78.1 \%)$ had complete remission ${ }^{[29]}$. Another systematic review included seven randomized controlled trials that revealed that bariatric surgery is an effective treatment for weight loss and resolution of obesity-related comorbidities, specifically T2DM ${ }^{[30]}$. A study conducted on 146 obese diabetic patients revealed that bariatric surgery resulted in complete resolution and improved control of diabetes with overall improvements in the quality of life [31].

Other results of bariatric surgery involve changes in the lipid profile ${ }^{[32]}$. Hypertriglyceridemia was found to be prevalent by two-folds among obese patients compared to non-obese individuals [33]. Atherogenic dyslipidemia, which is characterized by hypertriglyceridemia combined with low HDL and high LDL, is more prevalent in overweight and obese patients ${ }^{[34]}$.

A study compared between two techniques of bariatric surgery reported that both sleeve gastrectomy and Roux-en Y gastric bypass were effective in the improvement of the lipid profile; however, these improvements were dependent on the type of surgery, where Roux-en Y gastric bypass technique was more effective in improving the lipid profile as it resulted in improvements in the total cholesterol, HDL, LDL, and triglycerides ${ }^{[34]}$. A study conducted on patients who underwent laparoscopic sleeve gastrectomy revealed that there were 
improvements in the lipid profile after the surgery, with a significant increase in HDL and a considerable reduction in triglycerides and $\mathrm{LDL}^{[35]}$.

In Malaysia, bariatric surgery was found to be effective not only in weight loss but also in improving diabetes, dyslipidemia, and hypertension among obsess patients ${ }^{[36]}$. Moreover, the patients who performed bariatric surgery showed a reduction in the mortality rate after a mean follow-up of 10.9 years [37].

\section{Conclusion}

Bariatric surgery is effective on chronic diseases, including diabetes and dyslipidemia, regardless of the age of the patients. Bariatric surgery is more effective on diabetes mellitus; however, it is more affected by nationality and age. In the case of dyslipidemia, bariatric surgery is effective but with less degree compared to diabetes; however, isn't affected by the age of patients.

\section{References}

[1] Obesity and overweight, available at https://www.who.int/news-room/fact-

sheets/detail/obesity-and-overweight

[2] Dominguez, L. J., Galioto, A., Ferlisi, A., Pineo, A., Putignano, E., Belvedere, M., \& Barbagallo, M. (2006). Ageing, lifestyle modifications, and cardiovascular disease in developing countries. Journal of Nutrition Health and Aging, 10(2), 143.

[3] Mabchour, A. E., Delisle, H., Vilgrain, C., Larco, P., \& Sodjinou, R. (2016). Abdominal obesity and other cardiometabolic risk biomarkers: Influence of socioeconomic status and lifestyle on two African-origin population groups, Cotonou (Benin) and Port-au-Prince (Haiti). The Pan African Medical Journal, 24, 306-306.

[4] Ali, M. K., Bhaskarapillai, B., Shivashankar, R., Mohan, D., Fatmi, Z. A., Pradeepa, R., ... \& Prabhakaran, D. (2016). Socioeconomic status and cardiovascular risk in urban South Asia: The CARRS Study. European journal of preventive cardiology, 23(4), 408-419.

[5] Ball, K., \& Crawford, D. (2005). Socioeconomic status and weight change in adults: a review. Social science \& medicine, 60(9), 1987-2010.

[6] Mackenbach, J. P., Stirbu, I., Roskam, A. J. R., Schaap, M. M., Menvielle, G., Leinsalu, M., \& Kunst, A. E. (2008). Socioeconomic inequalities in health in 22 European countries. New England journal of medicine, 358(23), 2468-2481.

[7] Raymond, S. U., Leeder, S., \& Greenberg, H. M. (2006). Obesity and cardiovascular disease in developing countries: a growing problem and an economic threat. Current Opinion in Clinical Nutrition \& Metabolic Care, 9(2), 111-116.

[8] Leggio, M., Lombardi, M., Caldarone, E., Severi, P., D'emidio, S., Armeni, M., ... \& Mazza, A. (2017). The relationship between obesity and hypertension: an updated comprehensive overview on vicious twins. Hypertension Research, 40(12), 947-963.

[9] Aune, D., Sen, A., Norat, T., Janszky, I., Romundstad, P., Tonstad, S., \& Vatten, L. J. (2016). Body mass index, abdominal fatness, and heart failure incidence and mortality: a systematic review and dose-response metaanalysis of prospective studies. Circulation, 133(7), 639649.

[10] Morrison, Z., Douglas, A., Bhopal, R., \& Sheikh, A. (2014). Understanding experiences of participating in a weight loss lifestyle intervention trial: a qualitative evaluation of South Asians at high risk of diabetes. BMJ open, 4(6).

[11] Diabetes, view at https://www.who.int/news-room/factsheets/detail/diabetes

[12] Mingrone, G., Panunzi, S., De Gaetano, A., Guidone, C., Iaconelli, A., Leccesi, L., ... \& Rubino, F. (2012). Bariatric surgery versus conventional medical therapy for type 2 diabetes. New England Journal of Medicine, 366(17), 1577-1585.

[13] Sjöström, L. (2013). Review of the key results from the Swedish Obese Subjects (SOS) trial-a prospective controlled intervention study of bariatric surgery. Journal of internal medicine, 273(3), 219-234.

[14] Schauer, P. R., Kashyap, S. R., Wolski, K., Brethauer, S. A., Kirwan, J. P., Pothier, C. E., ... \& Bhatt, D. L. (2012). Bariatric surgery versus intensive medical therapy in obese patients with diabetes. New England Journal of Medicine, 366(17), 1567-1576.

[15] Acosta, A., Dayyeh, B. K. A., Port, J. D., \& Camilleri, M. (2014). Recent advances in clinical practice challenges and opportunities in the management of obesity. Gut, 63(4), 687-695.

[16] Guo, X., Liu, X., Wang, M., Wei, F., Zhang, Y., \& Zhang, Y. (2013). The effects of bariatric procedures versus medical therapy for obese patients with type 2 diabetes: meta-analysis of randomized controlled trials. BioMed research international, 2013.

[17] Avenell, A., Broom, J., Brown, T. J., Poobalan, A., Aucott, L., Stearns, S. C., ... \& Grant, A. M. (2004). Systematic review of the long-term effects and economic consequences of treatments for obesity and implications for health improvement. Health technology assessment, $8(21)$.

[18] Buchwald, H., \& Oien, D. M. (2013). Metabolic/bariatric surgery worldwide 2011. Obesity surgery, 23(4), 427436.

[19] Dixon, J. B., Le Roux, C. W., Rubino, F., \& Zimmet, P. (2012). Bariatric surgery for type 2 diabetes. The Lancet, 379(9833), 2300-2311.

[20] Fridman, A., Moon, R., Cozacov, Y., Ampudia, C., Menzo, E. L., Szomstein, S., \& Rosenthal, R. J. (2013). Procedure-related morbidity in bariatric surgery: a retrospective short-and mid-term follow-up of a single institution of the American College of Surgeons Bariatric Surgery Centers of Excellence. Journal of the American College of Surgeons, 217(4), 614-620.

[21] Aleassa, E. M., Hassan, M., Hayes, K., Brethauer, S. A., Schauer, P. R., \& Aminian, A. (2019). Effect of revisional bariatric surgery on type 2 diabetes mellitus. Surgical Endoscopy, 33(8), 2642-2648.

[22] Shimada, Y. J., Tsugawa, Y., Iso, H., Brown, D. F., \& Hasegawa, K. (2017). Association of bariatric surgery with risk of acute care use for hypertension-related disease in obese adults: population-based self-controlled case series study. BMC medicine, 15(1), 161. 
[23] Ricci, C., Gaeta, M., Rausa, E., Asti, E., Bandera, F., \& Bonavina, L. (2015). Long-term effects of bariatric surgery on type II diabetes, hypertension and hyperlipidemia: a meta-analysis and meta-regression study with 5-year follow-up. Obesity surgery, 25(3), 397405.

[24] Kashyap, S. R., Bhatt, D. L., Wolski, K., Watanabe, R. M., Abdul-Ghani, M., Abood, B., ... \& Kirwan, J. P. (2013). Metabolic effects of bariatric surgery in patients with moderate obesity and type 2 diabetes: analysis of a randomized control trial comparing surgery with intensive medical treatment. Diabetes care, 36(8), 21752182.

[25] Organization WH. Fact sheet: obesity and overweight (2006). www.who.int/dietphysicalactivity/ publications/facts/obesity/en

[26] Pischon $\mathrm{T}$, Boeing $\mathrm{H}$, Hoffmann $\mathrm{K}$, Bergmann $\mathrm{M}$, Schulze MB, Overvad K, Van der Schouw YT, Spencer E, Moons KG, Tjønneland A, Halkjaer J. (2008). General and abdominal adiposity and risk of death in Europe. New England Journal of Medicine. 13;359(20):2105-20.

[27] Buchwald H, Avidor Y, Braunwald E, Jensen MD, Pories W, Fahrbach K, Schoelles K. (2004). Bariatric surgery: a systematic review and meta-analysis. Jama. 13;292(14):1724-37.

[28] Dixon JB, O'Brien PE, Playfair J, Chapman L, Schachter LM, Skinner S, Proietto J, Bailey M, Anderson M. (2008). Adjustable gastric banding and conventional therapy for type 2 diabetes: a randomized controlled trial. Jama. 23;299(3):316-23.

[29] Buchwald H, Estok R, Fahrbach K, Banel D, Jensen MD, Pories WJ, Bantle JP, Sledge I. (2009). Weight and type 2 diabetes after bariatric surgery: systematic review and meta-analysis. The American journal of medicine. $1 ; 122(3): 248-56$

[30] Jackson HT, Anekwe C, Chang J, Haskins IN, Stanford FC. (2019). The role of bariatric surgery on diabetes and diabetic care compliance. Current diabetes reports.19(11):1-9.

[31] Dan D, Harnanan D, Singh Y, Hariharan S, Naraynsingh V, Teelucksingh S. (2011). Effects of bariatric surgery on type-2 diabetes mellitus in a Caribbean setting. International Journal of Surgery. 1;9(5):386-91.

[32] Tham JC, Howes N, le Roux CW. (2014). The role of bariatric surgery in the treatment of diabetes. Therapeutic advances in chronic disease. 5(3):149-57.

[33] Jellinger PS, Mehta AE, Smith DA, Handelsman Y, Ganda, O, Handelsman MD, Rodbard HW, Shepherd MD, Seibel JA (2012). AACE Task Force for Management of Dyslipidemia and Prevention of Atherosclerosis. American Association of Clinical Endocrinologists' Guidelines for management of dyslipidemia and prevention of atherosclerosis. Endocr Pract;18 Suppl 1:1-78.

[34] Lira, N. S., Macedo, C. E. S., Belo, G. M., Santa-Cruz, F., Siqueira, L. T., \& Ferraz, Á. A. B. (2018). Analysis of the lipid profile of patients submitted to sleeve gastrectomy and Roux-en-Y gastric bypass. Revista do Colegio Brasileiro de Cirurgioes, 45(6), e1967-e1967.

[35] Vigilante, A., Signorini, F., Marani, M., Paganini, V., Viscido, G., Navarro, L.,. \& Moser, F. (2018). Impact on dyslipidemia after laparoscopic sleeve gastrectomy. Obesity surgery, 28(10), 3111-3115.

[36] Tan, K. C., Chang, C. T., Cheah, W. K., Vinayak, C. R., \& Chan, H. K. (2019). Influence of bariatric surgery on weight reduction and control of chronic disease among obese patients in Malaysia. The Medical journal of Malaysia, 74(3), 215-218.

[37] Sjöström, L., Narbro, K., Sjöström, C. D., Karason, K., Larsson, B., Wedel, H.,. \& Carlsson, L. M. (2007). Effects of bariatric surgery on mortality in Swedish obese subjects. New England journal of medicine, 357(8), 741-752. 